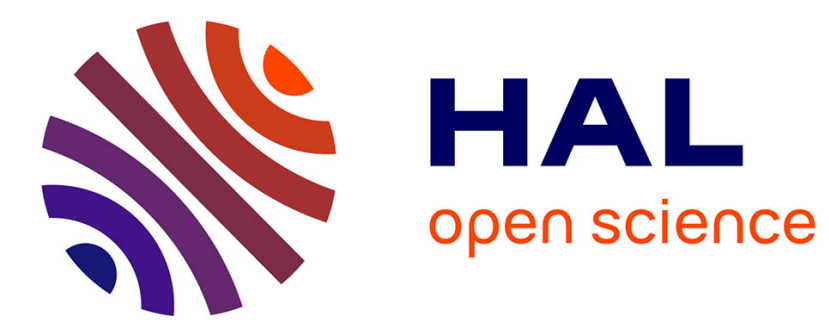

\title{
Particle size characterisation of in-flow milling products by video image analysis using global features
}

\author{
Bruno Novales, S. Guillaume, M.F. Devaux, Marc Chaurand
}

\section{To cite this version:}

Bruno Novales, S. Guillaume, M.F. Devaux, Marc Chaurand. Particle size characterisation of in-flow milling products by video image analysis using global features. Journal of the Science of Food and Agriculture, 1998, 78, pp.187-195. 10.1002/(SICI)1097-0010(199810)78:23.0.CO;2-3 . hal-02687241

\section{HAL Id: hal-02687241 \\ https://hal.inrae.fr/hal-02687241}

Submitted on 1 Jun 2020

HAL is a multi-disciplinary open access archive for the deposit and dissemination of scientific research documents, whether they are published or not. The documents may come from teaching and research institutions in France or abroad, or from public or private research centers.
L'archive ouverte pluridisciplinaire HAL, est destinée au dépôt et à la diffusion de documents scientifiques de niveau recherche, publiés ou non, émanant des établissements d'enseignement et de recherche français ou étrangers, des laboratoires publics ou privés. 


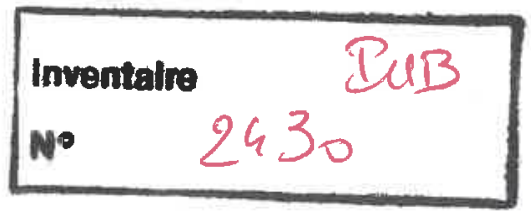

\title{
Particle Size Characterisation of In-Flow Milling Products by Video Image Analysis using Global Features
}

\author{
B Novales, ${ }^{1 *}$ S Guillaume, ${ }^{2}$ M F Devaux ${ }^{1}$ and M Chaurand ${ }^{3}$ \\ ${ }^{1}$ INRA Unité de Technologie Appliquée à la Nutrition, BP 7162744316 Nantes Cedex 03, France \\ 2 CEMAGREF Génie instrumental pour la qualité dans les industries agro-alimentaires BP 509534033
Montpellier Cedex, France \\ ${ }^{3}$ INRA Unité de Technologie des Céréales 2, place Viala, 34060 Montpellier, Cedex 01, France \\ (Received 27 May 1997; revised version received 7 November 1997; accepted 4 February 1998)
}

\begin{abstract}
The objective of this work was to characterise the particle size of milling products by image analysis. Four classes of milling products were obtained by varying the roll gap of the second break roll of the mill. Images were acquired by using an in-flow imaging system implemented in the mill, and 1300 images were recorded for each class. Three methods of image analysis were investigated: morphological opening, constant grey level run lengths and grey level spatial interdependences. Discriminant analyses were applied to the data extracted from the images by the three methods in order to identify each class of milling product. More than $77 \%$ of the samples were correctly assigned to their group, both for the calibration and validation sets. The best results were obtained by applying morphological openings or by computing parameters from the co-occurrence matrices. The number of correct classifications rose to $81 \%$ of samples with only three variables selected for the opening curves and to $83 \%$ with three co-occurrence parameters. (C) 1998 Society of Chemical Industry
\end{abstract}

J Sci Food Agric 78, 187-195 (1998) Key words: particle size; image analysis; morphological opening; run lengths;
co-occurrences

\section{INTRODUCTION}

The cereal milling process involves a succession of operations including breaking, separation and sieving, the objective of which are to fragment the grains and to separate the starchy endosperm from the bran. Breaking is achieved by a combination of rollers such as break and scratch rollers. The first breaking step is of major importance. The setting of the first break roll greatly determines the particle size of the milling products and is very important from an economical point of view (Godon and Willm 1994). For example, in durum wheat milling, which leads to the production of semolina, if the gap of the first break roll is set too close, it leads to the production of flour, which is considered as a by-

* To whom correspondence should be addressed. product. The control of the first breaking is generally done by visual and tactile assessment of the meal by the miller. Various systems for the on-line control of the breaking parameters have been proposed (McGee 1982; Berga 1988; Gamperle 1988). Recently, a prototype has been developed for the on-line measurement of the particle size of milling products just after the first breaking step (Ros et al 1994). This prototype consists of a video imaging system integrated in the mill. Images of the milling products are acquired in-flow and are processed by image analysis techniques.

Image analysis is commonly applied for the characterisation of object size and morphology and has been used for the measurement of particle size distribution (Zingerman et al 1992; Langton and Hermansson 1993). This method is of low cost in comparison with other techniques and allows on-line measurements even in

(C) 1998 Society of Chemical Industry. J Sci Food Agric 0022-5142/98/\$17.50. Printed in Great Britain 
hostile environments. Image analysis makes the study of single particles as well as sets of particles possible, and two approaches can be developed for the characterisation of the granulometric properties of powders. In the first approach, size and shape are measured for isolated particles, and the morphology of powders is described by the distributions observed for these parameters. This approach is the most commonly used for particle size determination by image analysis (Devaux $e t$ al 1992; Zingerman et al 1992). In the second approach, powders are characterised on the basis of textural features. Global measurements of the texture observed in the image can provide information about the size of the particles. It can be reasonably assumed that small particles lead to finer textures than larger particles. One advantage of textural methods is that there is no need to identify each particle individually. Two methods of texture analysis (constant grey level run lengths and grey level spatial interdependences) have been proposed for the characterisation of particle size. The constant grey level run length method characterises coarse textures as having more pixels in a constant grey level run than fine textures. This method has been applied by Bertrand et al (1991) for the characterisation of pea powders into five groups of varying particle size. The grey level spatial interdependences method characterises texture by the co-occurrences of grey tones. For coarse textures, the distribution changes slightly with distance; for fine textures, the distribution changes rapidly with distance. Sinfort et al (1992) have shown the interest of this method for the measurement of particle size on synthesis images.

Mathematical morphology represents another set of methods that allow the global characterisation of the size of objects observed in images (Serra 1982). The principle is to compare surfaces of the image with structuring elements of varying size and shape. By applying structural elements of increasing size, it is possible to continuously modify the images and obtain information concerning the size of the objects. A procedure called 'granulometric function' has been developed which directly gives the particle size distribution (Serra 1982). This procedure has been used by Devaux et al (1997) to study the granulometry of bulk powders.

In the present work, the objective was to characterise the particle size of milling products from images acquired while the process was running. The prototype developed by Ros et al (1994) for video on-line measurement was used. The mill was set with four different roll gaps leading to the production of four classes of milling products. Only global measurements were used for the characterisation of the milling products. Such measurements were considered to be more similar to the miller's assessment than individual counting. Three different image processings (opening, constant grey level run lengths and grey level spatial interdependences) were compared.

\section{MATERIAL AND METHODS}

\section{The pilot mill}

The breaking trials were carried out in the INRA semolina pilot mill (Abecassis 1994). The mill consists of nine roller mills. The first break roll (B1) is designed to shear the grain, while the second (B2) starts the process of separation between the endosperm and the barns. The other rolls reduce the particle size of the milling products and carry on the separation process. The mill was loaded with a durum wheat batch that had been cleaned and tempered up to $17 \%$ moisture content for $3 \mathrm{~h}$ prior to the milling. The setting of B1 was kept constant (roll-gap $0.70 \mathrm{~mm}$ ); the gap of $\mathrm{B} 2$ was set successively at $0.35,0.40,0.45$ and $0.50 \mathrm{~mm}$, leading to four classes of milling products E35, E40, E45 and E50.

The emerging products were analysed by mechanical sieving and by image analysis. A $100 \mathrm{~g}$ sample was sieved on a ROTEX laboratory sifter (TRIPETTE ET RENAUD, Paris, France) while image analysis was carried out on-line after the first breaking stage.

\section{Image acquisition system}

The prototype used for image acquisition was developed by Ros et al (1994). The image acquisition system was implemented after the first breaking stage where the main differences in grain milling are observed. The device consisted of a mechanical system that takes a representative part of the sample. The flow passes through a regulator designed to distribute the product over the whole width of the sampling slot without sorting the particles according to their size (Fig 1). A CCD (charge coupled device) camera (IVC 500, I2S, Bordeaux, France) synchronised with a strobe (flash duration set by the manufacturer at $20 \mu \mathrm{s}$ ) allows the visualisation of the falling particles. The images were digitised into $256 \times 256$ pixels with grey levels ranging

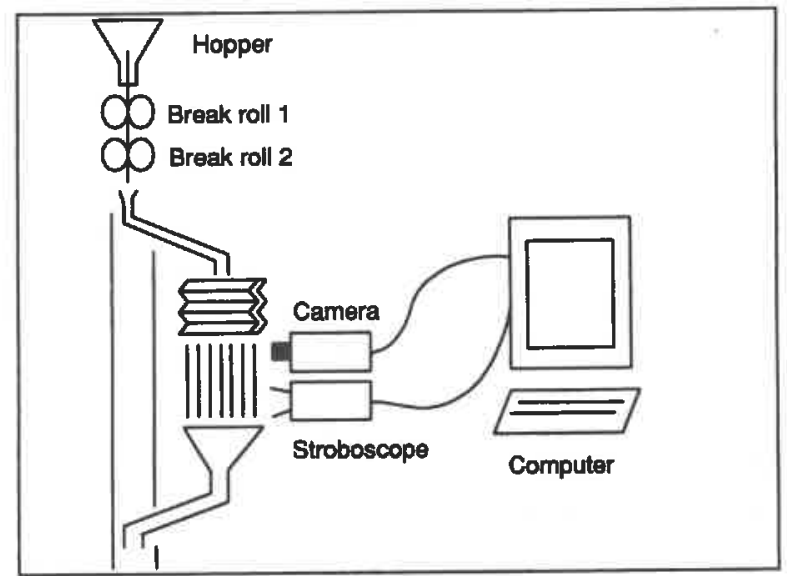

Fig 1. Diagram of the image acquisition system implemented in the experimental mill. 
from 0 to 255 . The area had dimensions of $64 \mathrm{~mm} \times 64 \mathrm{~mm}$. For each roll gap, 1300 images were recorded, giving 5200 independent images.

\section{Image processing}

Three methods of image analysis were applied: morphological opening, constant grey level run lengths and grey level spatial interdependences. Opening was performed on binary images that were obtained with a threshold set at 1 . All the pixels having a grey level above this value were considered as belonging to particles. For constant grey level run lengths and grey level spatial interdependences, the grey levels were grouped into four classes, and the class limits were dynamically computed for each image in order to create evenly populated classes. The background (grey level 0 ) represented a particular class which was not taken into account for statistics. The results of image processing were averaged for 10 images in order to ensure that a sufficient number of particles had been visualised to make the set representative of the product. Therefore, one sample was the result of the observation of the particles in 10 successive images.

\section{Opening}

A method for directly measuring particle size distributions from images consists in the successive application of a basic mathematical morphology procedure called 'opening' (Serra 1982). Opening is obtained by an erosion followed by a dilation applied to images by using a structuring element of a given size and shape. Erosion consists of giving to a reference pixel the minimum value observed among all the pixels covered by the structuring element. Dilation is the dual operation of erosion, whereby the maximum value observed in the area covered by the structuring element is assigned to the reference pixel. Only objects larger than the structuring element will survive the opening. When the size of the structuring element is increased, a smaller number of objects remains. A size distribution can be obtained by applying a sequence of openings with structuring elements of increasing size.

For this study, opening was applied to binary images with a squared structuring element and the reference pixel at the centre of the square. For each image, 10 opening steps were performed. At each step, the cumulated surface of remaining particles was computed. Granulometric curves were obtained by gathering the surface of the original binary image, followed by the values corresponding to the opening steps $1-10$. The surface values were average for 10 images and normalised by the initial surface. For each class, 130 curves were obtained and the resulting data table was made of 520 curves observed for 11 surface values. These granulometric curves were taken as cumulated particle size distributions measured as a percentage of the surface.

\section{Constant grey level run lengths}

A grey level run length is a set of consecutive pixels having the same grey level value. For each grey level, the number of runs which have a given length are counted for a given direction. The numbers of runs of different lengths and grey levels are stored in a two dimensional matrix called the run length matrix. This matrix can be represented as a set of curves where the runs are given according to the lengths and to the grey level values.

For this study, grey level runs were calculated for 11 length classes, the first 10 corresponding to run lengths of 1-10 pixels and the last corresponding to all the lengths greater than 10 pixels. Three directions were studied: East, North-east and North. The curves of run lengths were then constituted of 44 variables ( 4 grey level classes $\times 11$ lengths) for the three directions, leading to run length curves composed of 132 variables for each sample. After averaging, the resulting run length data table contained 520 curves of 132 variables. From the run numbers $C_{\mathrm{gl}}$ observed for each grey level $\mathrm{g}$ and each length 1 , texture parameters were computed. The following parameters proposed by Galloway (1975) were calculated:

\begin{tabular}{|c|c|}
\hline $\begin{array}{c}\text { Length uniformity: } \\
U_{\text {length }} \\
\text { let } M_{1}^{\mathrm{r}} \text { be the order } \mathrm{r} \\
\text { moment of the lengths } \\
M_{\mathrm{I}}^{\mathrm{r}}=\frac{\sum_{\mathrm{g}} \sum_{1} C_{\mathrm{gl}} 1^{\mathrm{x}}}{\sum_{\mathrm{g}} \sum_{1} C_{\mathrm{gl}}} \\
U_{\text {length }}=\frac{M_{1}^{4}}{\left(M_{1}^{2}\right)^{2}}\end{array}$ & $\begin{array}{c}\text { Grey levels uniformity } \\
U_{\text {grey }} \\
\text { let } M_{\mathrm{g}}^{\mathrm{r}} \text { be the order } \mathrm{r} \\
\text { moment of the grey } \\
\text { level } \\
g_{\mathrm{m}} \text { the average grey } \\
\text { level of the class } \\
M_{\mathrm{g}}^{\mathrm{r}}=\frac{\sum_{\mathrm{g}} \sum_{1} C_{\mathrm{g} 1}\left(g_{\mathrm{m}}\right)^{\mathrm{r}}}{\sum_{\mathrm{g}} \sum_{1} C_{\mathrm{gl}}} \\
U_{\mathrm{grey}}=\frac{M_{\mathrm{g}}^{4}}{\left(M_{\mathrm{g}}^{2}\right)^{2}}\end{array}$ \\
\hline $\begin{array}{c}\begin{array}{c}\text { Short run } \\
\text { indicator: } I_{\mathrm{c}}\end{array} \\
I_{\mathrm{c}}=\frac{\sum_{\mathrm{g}} \sum_{1} C_{\mathrm{gl}} /(1)^{2}}{\sum_{\mathrm{g}} \sum_{1} C_{\mathrm{gl}}}\end{array}$ & $\begin{array}{c}\begin{array}{c}\text { Long run } \\
\text { indicator: } I_{1}\end{array} \\
I_{1}=\frac{\sum_{\mathrm{g}} \sum_{1} C_{\mathrm{gl}}(1)^{2}}{\sum_{\mathrm{g}} \sum_{1} C_{\mathrm{gl}}}\end{array}$ \\
\hline
\end{tabular}

The ratio $I_{V} / I_{\mathrm{c}}$ was also calculated for the three directions. The resulting variables were gathered in a vector of 15 variables, leading to a data table of 520 observations for 15 values.

Grey level spatial interdependence method (co-occurrence method)

This method is based on the observations of grey level values for pairs of pixels separated by a given distance in a given direction. The result is a two-dimensional histogram describing the probability that pairs of grey level values occur in a given spatial relationship. For 
this study, only adjacent pixels were considered in the three directions. The number of times $C_{\mathrm{rc}}$ that a pixel of grey level $\mathbf{r}$ was found adjacent to a pixel of grey level $c$ was computed in each direction. The frequencies of occurrences were arranged into square tables called the co-occurrence matrices, whose size is equal to the number of grey level classes. The backgroundbackground transitions were not taken into account, and 24 variables were obtained for each direction. The raw co-occurrence data table was constituted of 520 vectors of 72 values (24 variables for three directions). From each co-occurrence matrix, the following parameters (Haralick 1979) were computed (where $g_{\mathrm{rc}}$ is the difference between the average grey levels of the row and the column):

\begin{tabular}{|c|c|}
\hline $\begin{array}{l}\text { Inertia } \\
\qquad=\frac{\sum_{\mathrm{r}} \sum_{\mathrm{c}}\left(C_{\mathrm{rc}}(\mathrm{r}-\mathrm{c})^{2}\right)}{\sum_{\mathrm{r}} \sum_{\mathrm{c}} C_{\mathrm{rc}}}\end{array}$ & $\begin{array}{l}\text { Heterogenity } \\
\qquad=\frac{\sum_{\mathrm{r}} \sum_{\mathrm{c}}\left(C_{\mathrm{cr}}\right)^{2}}{\left(\sum_{\mathrm{r}} \sum_{\mathrm{c}} C_{\mathrm{rc}}\right)^{2}}\end{array}$ \\
\hline $\begin{array}{l}\text { Entropy } \\
=\frac{\sum_{\mathrm{r}} \sum_{\mathrm{c}}\left(C_{\mathrm{rc}} \ln \left(C_{\mathrm{cr}}\right)\right)}{\sum_{\mathrm{r}} \sum_{\mathrm{c}} C_{\mathrm{rc}} \ln \left(\sum_{\mathrm{r}} \sum_{\mathrm{c}} C_{\mathrm{rc}}\right)}\end{array}$ & $\begin{array}{l}\text { Contrast } \\
=\frac{\sum_{\mathrm{r}} \sum_{\mathrm{c}}\left(C_{\mathrm{rc}} g_{\mathrm{rc}}^{2}\right)}{\sum_{\mathrm{r}} \sum_{\mathrm{c}} C_{\mathrm{rc}}}\end{array}$ \\
\hline
\end{tabular}

The maximum of probability (maximum of $C_{\mathrm{rc}}$ ) was also extracted from the matrices: The co-occurrence parameters data table was constituted of 520 vectors of 15 values ( 5 parameters for each of the three directions).

\section{Data processing}

In order to create calibration and validation sets, the data tables were arbitrarily divided into two groups of 260 samples each. The two groups were used successively as calibration and validation set for all the mathematical treatments. The objective was to verify that the results did not greatly vary when the two sets were inverted.

The four qualitative groups corresponding to the four roll gaps were predicted by stepwise discriminant analysis (SDA). This method selects among a set of variables those which best predict the qualitative groups (Romeder 1973). The gravity centres of the groups are computed and each sample is attributed to the closest group according to the Euclidean distances calculated from the selected variables. The percentage of samples correctly classified is calculated. In the present work, variables were introduced step by step until the percentage of samples correctly classified in the validation set no longer increased. This procedure prevents overfitting and ensures that a minimum number of variables is selected.

SDA was applied to the opening curves, the run length and co-occurrence parameters. More than 70 variables were available in the case of the run length and co-occurrence matrices. These two data tables were therefore subjected to a preliminary processing by principal component analysis (PCA), which is widely used to study large data tables. By this method, synthetic variables called 'principal components' are calculated from the original variables. The principal components are uncorrelated and describe the main variations observed among the samples (Jolliffe 1986). SDA was applied to the principal components calculated from the run length and co-occurrence matrices.

Factorial discriminant analysis (FDA) was applied to the sets of selected variables in order to calculate discriminant variables called 'discriminant factors'. These factors make possible the drawing of the discriminant maps in which the groups are best separated (Romeder 1973).

\section{RESULTS}

\section{Sieving}

Particle size distributions of the four classes of milling product were measured by sieving and are shown in Fig 2. The number of fine particles (particle size ranging from 230 to $1100 \mu \mathrm{m}$ ) decreased when the roll gap increased. On the contrary, coarse particles (particle size over $1230 \mu \mathrm{m}$ ) increased with the roll gap. The average diameters were $1180,1290,1340$ and $1410 \mu \mathrm{m}$ for classes $\mathrm{E} 35, \mathrm{E} 40, \mathrm{E} 45$ and $\mathrm{E} 50 \mathrm{~mm}$, respectively. The distributions corresponding to roll gaps at 0.40 and $0.45 \mathrm{~mm}$ were rather close to each other.

\section{Image processing}

Few differences in the particle size could be seen by visual observation of the images. The average opening

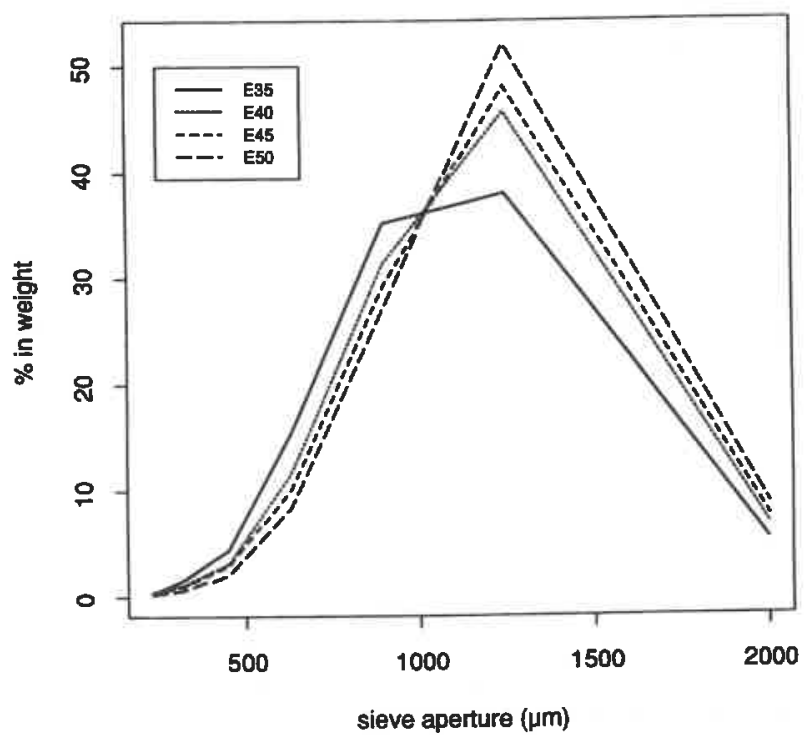

Fig 2. Particle size distributions obtained by sieving. 


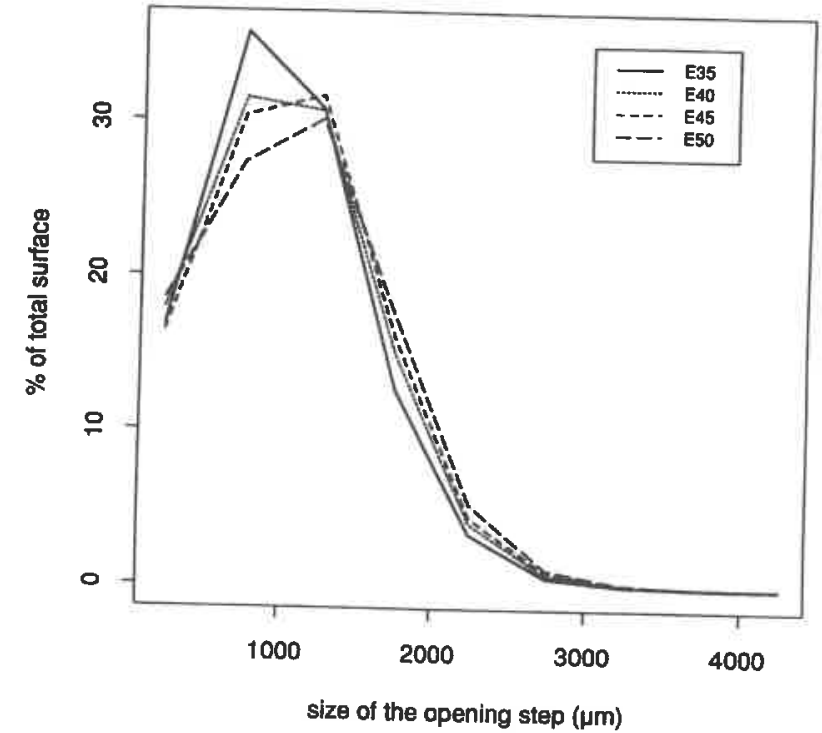

Fig 3. Average opening curves of the four classes of milling products.

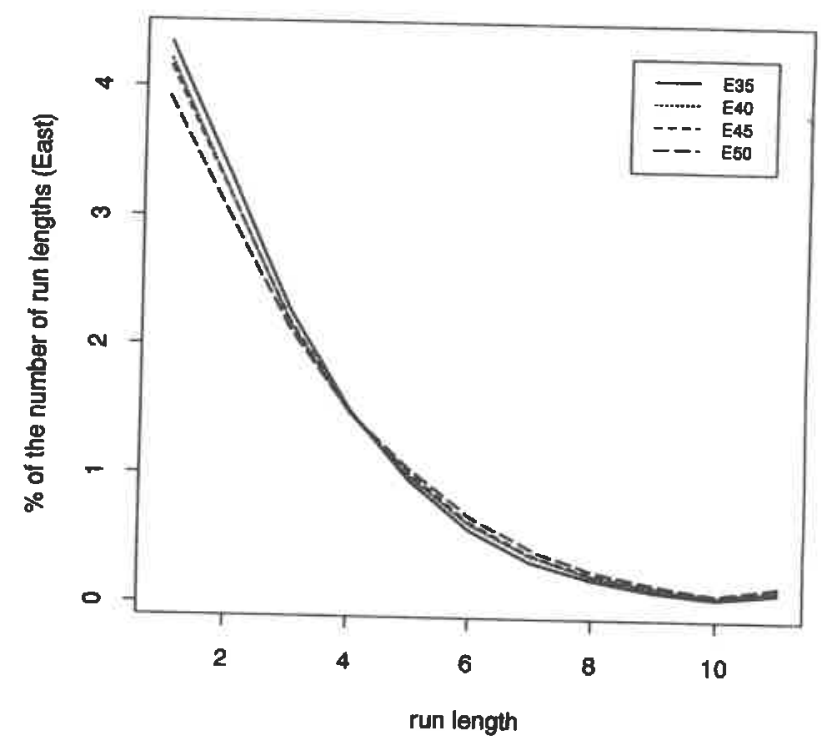

Fig 4. Average run length curves of the four classes of milling products. Only runs of grey level class 4 in direction East are represented.

TABLE 1

Grey level spatial interdependences: averaged occurrences for grey level class 4 to class 4 for the four milling products clas$\operatorname{ses}^{a}$

\begin{tabular}{cccc}
\hline $\begin{array}{c}\text { Roll gap } \\
\text { setting }(\mathrm{mm})\end{array}$ & East & North-east & North \\
\hline 0.35 & 13.28 & 10.73 & 13.58 \\
0.40 & 13.54 & 11.10 & 13.88 \\
0.45 & 13.65 & 11.21 & 13.99 \\
0.50 & 13.86 & 11.56 & 14.22 \\
\hline
\end{tabular}

${ }^{a}$ Numbers are expressed in percentage of the total number of occurrences for each direction. curves obtained for the four classes of milling products are given in Fig 3. Seven opening steps were sufficient to make the largest particles disappear. The largest differences in the curves were observed for step 2 . The four curves were in the same order as those obtained by sieving. As the opening curves can be interpreted as particle size distribution, it is possible to calculate an average particle size from the curves. The values were $1145,1188,1217$ and $1243 \mu \mathrm{m}$ for the four classes, respectively, and differ slightly from the values obtained by sieving. This might be explained by the fact that sieving corresponds to weight measurement, whereas opening curves correspond to surface measurements.

The constant grey level run lengths were computed for 11 lengths and for the three analysed directions, giving 132 values (3 directions $\times 4$ grey level classes $\times 11$ lengths) for each sample. The largest differences were observed for the runs constituted of pixels of high grey levels (classes 4 and 3) for the three analysed directions (data not shown). These runs corresponded to the inner parts of the particles. Figure 4 shows the part of the average run length curves measured for grey level class 4 in the direction East. The curves drawn on the figure indicate that the number of small runs (lower than four pixels) decreases with the roll gap, while the number of large runs increases. The curves obtained for classes $\mathrm{E} 40$ and $\mathrm{E} 45$ were almost similar.

The matrices of grey level spatial interdependences (co-occurrence matrices) were extracted from each image. Table 1 shows the number of pairs of pixels both belonging to class 4 (i.e. $C_{44}$ ) in the three directions averaged for each class of milling products. In the table, the number of co-occurrences is expressed as a percentage of the total number of co-occurrences. The cooccurrences $C_{44}$ corresponded to particle-particle transitions and were the most represented in the three directions. These co-occurrences were correctly ordered according to the four groups of milling products. The values did not vary much from one roll gap to the other, and the corresponding standard deviations were about $0 \cdot 17$, showing a large overlap between the groups.

\section{Particle size characterisation}

SDA was applied to all the different data sets in order to select the most relevant variables for the discrimination of the four qualitative groups corresponding to the four roll gaps. The overall percentages of correct classification for the calibration and validation sets are reported in Table 2 for the different analyses. For each method, lines $a$ and $b$ give the results obtained when the calibration and validation sets were inverted. Although human visual observation of the images did not allow the discrimination between the four classes of milling products, the three image processing methods used in this study successfully classified the validation samples 
TABLE 2

Stepwise discriminant analyses ${ }^{a}$

\begin{tabular}{|c|c|c|c|c|c|}
\hline \multirow[t]{2}{*}{ Parameters } & & \multicolumn{4}{|c|}{ Percentage of correct classification } \\
\hline & & Calibration set & $\begin{array}{l}\text { Validation set } \\
\text { parameters }\end{array}$ & Number of & Parameters introduced \\
\hline Opening & $\begin{array}{l}a \\
b\end{array}$ & $\begin{array}{l}84 \\
85\end{array}$ & $\begin{array}{l}81 \\
84\end{array}$ & $\begin{array}{l}3 \\
3\end{array}$ & $\begin{array}{l}\text { Opening steps } 4,2 \text { and } 3 \\
\text { Opening steps } 4,2 \text { and } 3\end{array}$ \\
\hline Run length matrices & $\begin{array}{l}a \\
b\end{array}$ & $\begin{array}{l}80 \\
81\end{array}$ & $\begin{array}{l}77 \\
77\end{array}$ & $\begin{array}{l}5 \\
5\end{array}$ & $\begin{array}{l}\text { PC } 2,1,3,8 \text { and } 4 \\
\text { PC } 2,1,3,4 \text { and } 8\end{array}$ \\
\hline Run length parameters & $a$ & 80 & $\begin{array}{l}78 \\
78\end{array}$ & $\begin{array}{l}2 \\
2\end{array}$ & $\begin{array}{l}\text { East ratio } I_{\mathrm{l}} / I_{\mathrm{c}} \\
\text { East grey level uniformity } \\
\text { North-east ratio } I_{\sqrt{ }} / I_{\mathrm{c}} \\
\text { East grey level uniformity }\end{array}$ \\
\hline Co-occurrence matrices & $\begin{array}{l}a \\
b\end{array}$ & $\begin{array}{l}79 \\
80\end{array}$ & $\begin{array}{l}81 \\
79\end{array}$ & $\begin{array}{l}3 \\
3\end{array}$ & $\begin{array}{l}\text { PC } 1,2 \text { and } 3 \\
\text { PC } 1,2 \text { and } 3\end{array}$ \\
\hline Co-occurrence parameters & $b$ & 83 & 83 & 3 & $\begin{array}{l}\text { East heterogeneity } \\
\text { North-east contrast } \\
\text { East inertia } \\
\text { North heterogeneity } \\
\text { East inertia } \\
\text { East contrast }\end{array}$ \\
\hline
\end{tabular}

${ }^{a}$ Lines $a$ and $b$ correspond to the inversion of the calibration and validation sets.

with an average confidence greater than $77 \%$. With the morphological openings, three variables were selected, corresponding to the 4th, 2nd and 3rd opening steps. The sizes of these openings were 1750,750 and 1250 $\mu \mathrm{m}$, respectively, and covered the range of the average diameters observed for the four classes. They corresponded to the part of the curves where the main variations were observed (Fig 3). The percentages of correct classification were 81 and 84 of the samples in the validation sets. In the case of the run length processing, the discrimination was applied to the principal components obtained from the raw matrices and on the parameters extracted from the matrices. The percentage of wellclassified samples was 77 for the matrices and 78 for the parameters. Five components were necessary with the run length matrices, and only two variables were sufficient with the parameters. In the case of the parameters, the first variable introduced in the discrimination was not the same when the calibration and validation sets were inverted. The ratio of the long run indicator over the short run indicator $\left(I_{1} / I_{\mathrm{c}}\right)$ for direction East was replaced by the ratio for direction North. These two variables were in fact correlated with a correlation coefficient of 0.98 . The co-occurrence image processing gave around $80 \%$ of samples correctly classified in the validation sets by selecting the first three principal components calculated from the matrices. The classification rose to $83 \%$ with three co-occurrence parameters intro-

TABLE 3

Classification tables obtained by discriminant analysis of the openings and co-occurrence parameters

\begin{tabular}{|c|c|c|c|c|c|c|c|c|c|}
\hline & & \multicolumn{4}{|c|}{ Openings } & \multicolumn{4}{|c|}{ Co-occurrences } \\
\hline & & E35 & $E 40$ & $E 45$ & E50 & E35 & $E 40$ & $E 45$ & E50 \\
\hline \multirow[t]{4}{*}{ Calibration set } & E35 & 95 & 5 & - & - & 83 & 11 & 6 & 一 \\
\hline & E40 & - & 77 & 23 & - & 3 & 82 & 15 & - \\
\hline & E45 & 3 & 18 & 69 & 11 & - & 14 & 78 & 8 \\
\hline & E50 & - & - & 5 & 95 & - & 2 & 9 & 89 \\
\hline \multirow[t]{4}{*}{ Validation set } & E35 & 95 & 5 & - & - & 86 & 14 & - & - \\
\hline & $\mathrm{E} 40$ & - & 68 & 32 & - & - & 75 & 23 & 2 \\
\hline & $\mathrm{E} 45$ & 3 & 25 & 66 & 6 & 5 & 9 & 80 & 6 \\
\hline & E50 & - & - & 6 & 94 & - & - & 9 & 91 \\
\hline
\end{tabular}




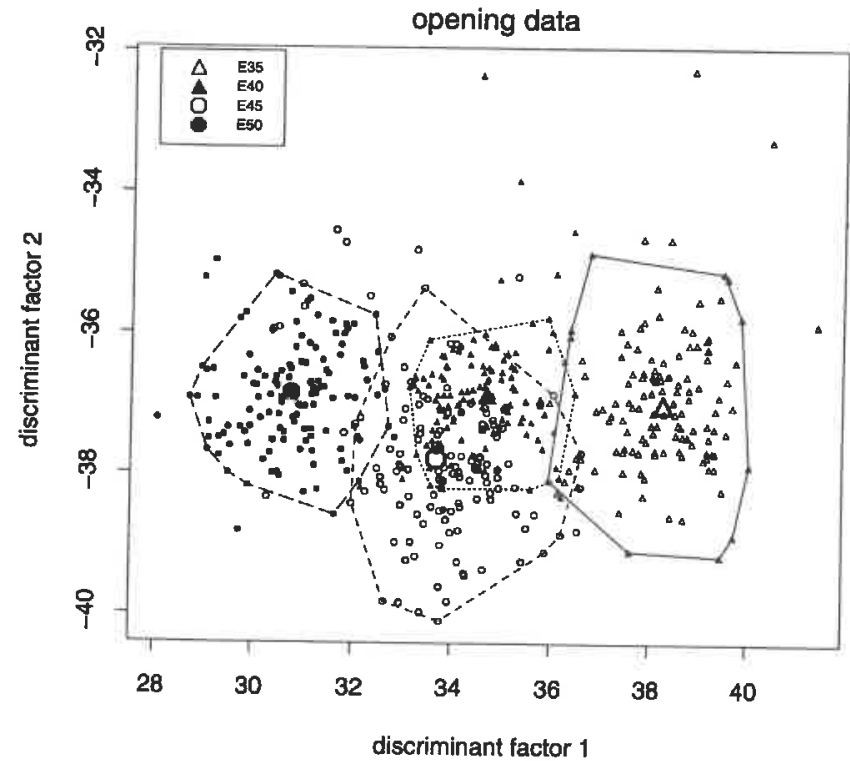

Fig 5. Factorial discriminant analysis of the opening variables selected by stepwise discriminant analysis: opening steps 2,3 and 4. The similarity map is drawn from discriminant factors 1 and 2. For each group, a polygon is drawn to surround the $90 \%$ of samples that were the closest to the gravity centre.

duced in the model. Two of these parameters were different when the calibration and validation sets were inverted. The East heterogeneity was replaced by the North heterogeneity $(r=0.98)$, and the North-east contrast was replaced by the East contrast $(r=0.99)$.

The discrimination was improved when the run length and co-occurrence parameters were used in comparison with the discriminations obtained by using the

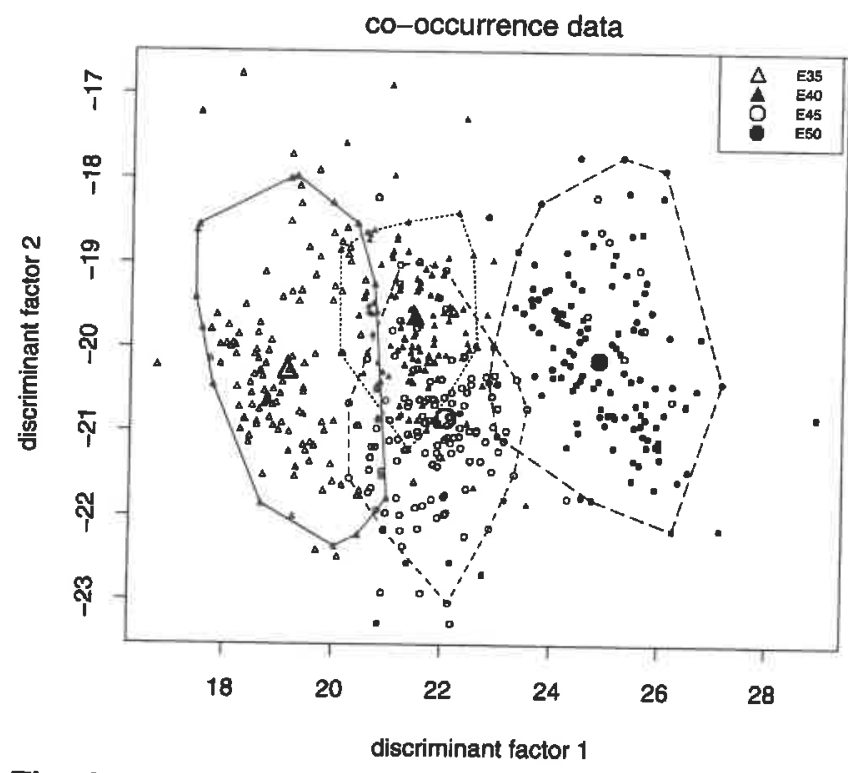

Fig 6. Factorial discriminant analysis of the three cooccurrence parameters selected by stepwise discriminant analysis: East heterogeneity, North-east contrast and East inertia. The similarity map is drawn by discriminant factors 1 and 2. For each group, a polygon is drawn to surround the $90 \%$ of samples that were the closest to the gravity centre. raw matrices. This result showed that the parameters assessed for both methods are relevant to extract some information concerning the particle size from the matrices. Among the run length parameters, the ratio $I_{1} / I_{c}$ and the grey level uniformity were the most affected by variations in the particle size. In the case of the co-occurrences, the heterogeneity, the inertia and the contrast clearly depended on the size of the milling products.

The two discriminations obtained by using morphological openings and co-occurrence parameters led to the highest percentages of correct classification. The attributions of the samples to the groups were examined more precisely for these two methods (Table 3). Classes E35 and E50 were the most easily identified, with about $95 \%$ of samples correctly classified by using the opening variables. Classes E40 and E45 were often confused, as about $30 \%$ of samples were mis-classified. In the case of the co-occurrence parameters, less differences were observed between the four groups, with percentages of correct classification varying from 75 to $91 \%$. For both methods, the confusions occurred principally between adjacent classes.

FDA was performed on the three opening steps and on the co-occurrence parameters selected by SDA. The objective was to visualise the four qualitative groups according to the discriminant factors. The two discriminant maps are shown in Figs 5 and 6. For each group, polygons were drawn to surround the $90 \%$ of samples that were the closest to the gravity centres. The groups were separated according to the particle size along the first discriminant factor. In both cases, classes E35 and E50 were located at opposite ends, while classes E40 and E45 were found at the centre of the map. Class E35 was separated further from classes E40 and E45 by using the opening variables. The two intermediate groups E40 and E45 largely overlapped by both methods. The separation of these two groups was improved when using the co-occurrence parameters. The maps in fact provide a visual representation of the classifications reported in Table 3.

\section{DISCUSSION}

The global processing used in the present work was found to be useful for the determination of the particle size of in-flow milling products.

Morphological opening is simple to implement and the results obtained by this method are easy to interpret. This image data treatment provides curves that can be taken as usual particle size distributions. This kind of image processing is comparable with a digital sieving. At each opening step, particles smaller than the opening size are eliminated from the image, and the remaining surface is measured. One advantage is that no assumption is made concerning the shape and the 
overlapping of the particles. Even when particles touch in the image, the particle size measurement is little affected, as the measurement is global.

The results obtained by applying the grey level run lengths, both when using the matrices or the parameters, were slightly poorer than those obtained by the openings and the spatial interdependences. Bertrand et al (1991), who applied this method on pea bulk powders, obtained $75 \%$ of samples correctly classified from the run length matrices. This result can be compared with the $77 \%$ of samples correctly classified in the present work.

In the case of the spatial grey level interdependence processing, the co-occurrence parameters were found to be more efficient than the matrices to discriminate the four groups of milling products. Many parameters can be computed from the co-occurrence matrices (Haralick et al 1973). Five of them were used in the present study, among which the heterogeneity, inertia and contrast were the most predictive. Inertia and contrast take into account some information concerning the grey levels of the pixels considered. This may be one reason for having a better prediction from the parameters than from the raw matrices. The co-occurrence matrices were built by only considering spatial interdependences between adjacent pixels. Matrices could have been assessed from more distant pixels. In the present work, the particles were randomly disposed on a black background in the images. The method was used to determine the particle size and not to identify a structured texture.

No preferential direction could be found in the position of the particles on the images by visual observation. This was verified by applying grey level run lengths and spatial interpendences in three directions: East, North and North-east. The parameters introduced for the discrimination were identical, except that they were calculated for different directions. As the parameters replaced were highly correlated, this result confirmed that there was no preferential direction in the images, as can be observed in the examples given in Fig 3. The two calibration sets led to the selection of the same kind of parameters assessed for different processed directions. This result suggests that one direction would be sufficient to characterise the particle size of in-flow milling products. In the case of the co-occurrence processing, the three directions were analysed separately. The percentages of samples correctly classified were 83.5 on average, and ranged between 81 and 87 . The same three parameters were always selected, namely heterogeneity, inertia and contrast. These results prove that, in the current milling application, only one direction would be sufficient for future experiments.

Guillaume et al (1996) have previously used the same video imaging system to discriminate three settings of the roll gap: $0.30,0.40$ and $0.50 \mathrm{~mm}$. They combined textural descriptors with individual analyses of the par- ticles after their identification in the images. They could classify $81.6 \%$ of the samples. Class E30 was completely identified, while classes E40 and E50 were confused, with 19 and $36 \%$ of samples mis-classified, respectively. In the present work, only global image processings were applied. Images of milling products were collected for four roll gap settings: $0.35,0.40,0.45$ and $0.50 \mathrm{~mm}$. The average percentages of samples correctly classified from the opening curves or from the co-occurrence parameters were higher than 81 . The classification was improved in the present work in comparison with the results of Guillaume et al. The accuracy of the system has been increased by setting roll gap steps of $0.05 \mathrm{~mm}$ instead of $0.10 \mathrm{~mm}$, and the discrimination has been achieved using only global features.

\section{CONCLUSION}

Image analysis has been used to characterise the size distribution of milling products and to identify the roll gaps set to obtain these products. Morphological opening, constant grey level run lengths and grey level spatial interdependences have been studied. Few differences could be found by a simple visual observation of the images. The three methods used in the study made it possible to classify the samples according to the four classes of milling products, with more than $77 \%$ correct classification. The best results were obtained by morphological openings and by assessing the parameters from the co-occurrence matrices. The great advantage of these methods is that they do not require each particle to be identified. Moreover, no prior hypothesis upon the shape of the particles is needed with such global image processings.

\section{REFERENCES}

Abecassis J 1994 Hard wheat milling. In: Primary Cereal Processing, ed Godon B \& Willm C. VCH, New York, USA, pp 291-317.

Berga 1988 Optimizer per l'automazione della macinazione. Tec Mol 3 250-251.

Bertrand D, Robert P, Melcion J P, Sire A 1991 Characterisation of powders by video image analysis. Powder Technol 66 171-176.

Devaux M F, Qannari E M, Gallant D J 1992 Multiplecorrespondence analysis optical microscopy for determination of starch granules. $J$ Chemometr 6 163-175.

Devaux M F, Robert P, Melcion J P, Le Deschault de Monredon F 1997 Particle size analysis of bulk powders using mathematical morphology. Powder Technol 90 141-147.

Galloway M 1975 Texture analysis using grey level run lengths. Comp Graph Image Proc 4 171-179.

Gamperle J 1988 Etat actuel des recherches en vue de l'automatisation totale d'un moulin. Ind Céréal 51 9-14.

Godon B, Willm C 1994 Primary cereal processing: a comprehensive source book. VCH, New York, USA. 
Guillaume S, Ros F, Chaurand M, Bellon-Maurel V, Abécassis J 1996 Characterization of mill products by analysis of in-flow digitalized images. $J$ Food Engng 27 311-322.

Haralick R M 1979 Statistical and structural approaches to texture. Proc IEEE 67 786-804.

Haralick R M, Shanmugam K, Dinstein I 1973 Textural features for image classification. IEEE Trans Syst Man Cybernet 3 610-621.

Langton M, Hermansson A M 1993 Image analysis determination of particle size distribution. Food Hydrocoll 7 11-22.

Jolliffe I T 1986 Principal Component Analysis. Springer, New York, USA.

McGee B 1982 Milling: it's time to automate. Food Manufact $5736-37$.
Romeder J M 1973 Méthodes d'Analyse Discriminante. Dunod, Paris, France.

Ros F, Guillaume S, Bertrand D, Rabatel G, Sevila F 1994 Optics in Agriculture, Forestry and Biological Processing. SPIE, Boston, USA, pp 120-127

Serra J 1982 Image Analysis and Mathematical Morphology. Academic Press, London, UK.

Sinfort N, Bellon V, Sevila F 1992 Image analysis for in-flow measurement of particle size. Food Contr 3 84-90.

Zingerman J P, Mehta S C, Salter J M, Radebaugh G W 1992 Validation of a computerized image analysis system for particle size determination: pharmaceutical applications. Int $J$ Pharm 88 303-312. 
